\title{
The Long Term Effect of Compression in Lower Limb Edema During Pregnancy: A Case Report
}

\author{
Katarzyna Ochalek* \\ University Of Physical Education, Poland
}

Submission: December 09, 2019; Published: December 17, 2019

*Corresponding author: katarzyna ochalek, university of physical education, poland

\section{Abstract}

Lower limb edema with its accompanying subjective ailments, is a frequent condition in pregnant women and in the postpartum period. In this case report, we present a case of lower limb edema in the 33rd week of pregnancy when the compression therapy (CT) initiating with compressive bandaging (CB) was applied and the further improvement by use of compression garments (CG) before and after delivery, and 3 years later.

Keywords: Compression therapy; Compression garments; Compressive bandaging; Pregnancy; Lower Limb Edema

Abbreviatations: CT: Compression Therapy; CB: Compressive Bandaging; CG: Compression Garments; LLV: Lef Limb Volume; RLF: Right Limb Volume

\section{Introduction}

Lower limb edema is increasingly frequent in gravid women during the third trimester of pregnancy $[1,2]$. It occurs as a result of venous hypertension mainly caused by mechanical obstruction of the venous flow in the pelvis The unquestionable method applied in the prevention and treatment of the venous-lymphatic dysfunctions is compression therapy (CT) involving compressive bandaging (CB) and wearing compression garments (CG) [3]. Literature concerning the application of CT in pregnancy and postpartum period is scarce. In this case report we describe a woman in the $33 \mathrm{rd}$ week of first pregnancy with lower limb edema and the effect of CT.Written informed consent was obtained for the publication of this case report.

\section{Case Report}

A 32 -year old woman, in her 33rd week of first physiological pregnancy was referred to our Lymphedema Clinic with lower limb edema and accompanying subjective ailments as soreness, the feeling of heaviness of legs, paresthesia, burning sensation, and nocturnal cramps. On physical examination, the swelling was localized on both legs, mainly in the dorsal region of both feet and lower legs with a pitting consistency. The Stemmer's sign (thickened fold of the skin at the base of the toes in the foot), which is classically measured at in patients with lower extremity swelling, was positive. In ultrasonography, patency of the superficial and deep veins on both sides were found. "Beginning of chronic vein insufficiency with insufficient perforators" on the ride side was described. Venous status according to CEAP classification was C3s. She had no history of thrombophlebitis, or thromboembolic events. Despite these venous disturbances, no CT during pregnancy was recommended by the consultant vascular surgeon. After physical evaluation in the Lymphedema Clinic we started the physiotherapeutic managament with use of CT. In the first phase of the treatment CB (short-stretch bandages) in combination with skin care were applid every day for two weeks and the patient was encouraged to walk.

At the end of the intensive treatment circular knit compression stockings (23-32 mmHg, German RAL Class II) were prescribed, wearable during day, before delivery and in the postpartum period. Circumference measurements were taken before treatment, after one day and two weeks, and one and three years aftery delivery. Leg volumes were calculated based on the truncated cone formula [4]. The greatest improvements with respect to the decrease in size of the swelling and changes in the consistency were observed in the first days of therapy. After one and three years, further 
improvement from continuing of CG in limb volumes change were observed. The positive influence of compression on subjective symptoms, especially pain improving quality of life was also observed. Changes in the limb volumes are presented in Table 1.

Table 1: Lower limb volumes before and after treatment.

\begin{tabular}{|c|c|c|c|c|c|c|c|}
\hline Treatment Phase & Consistency & LLV & RLV & Change & Change & Change & Change \\
\hline Before admission & of edema & {$[\mathrm{ml}]$} & {$[\mathrm{ml}]$} & LLV[ml] & $\mathrm{RLV}[\mathrm{ml}]$ & $\%$ & $\%$ \\
\hline Before admission & +++ & 3478 & 3395 & & & & \\
\hline Intensive 1 day & ++ & 3024 & 3146 & -454 & -249 & -13 & $-7,9$ \\
\hline Intensive 2 weeks & + & 2997 & 3007 & -481 & -388 & $-13,8$ & $-11,4$ \\
\hline Maintenance1 year & - & 2613 & 2592 & -865 & -803 & $-24,8$ & $-23,6$ \\
\hline
\end{tabular}

LLV-lef limb volume; RLF-right limb volume; +++-intensity of edema.

\section{Discussion}

Despite lower limb edema with its accompanying conditions concerns as many as about $80 \%$ of pregnant women, especially during the second and third trimesters [1] like in our presented case report, literature concerning the application of CT in the management of lower limb edema during pregnancy and postpartum period is scarce. The link between venous disease and pregnancy is well known but has rarely been described from symptomatic point of view [5]. There is also lack of qualitinative data concerning bilateral lower extremity volume during pregnancy. Only few data are available on the effect of wearing CG on subjective symptoms and quality of life of pregnant women in daily practice $[2,5]$. In a recent study we demonstrated that chronic venous insufficiency, arterial hypertension and venous thrombosis diagnosed before pregnancy, as well as the lack of physical activity during pregnancy, contributed to the development of lower limb edema [6]. Interdependance was observed between the occurance of edema during pregnancy and such conditions before pregnancy as chronic venous insufficiency. Immediate compression including $\mathrm{CB}$ with mobilization is recommended to reduce the swelling and pain in acute vein thrombosis during pregnancy [2]. It should be considered in all women with recognized edema especially with venous flow abnormalities diagnosed before pregnancy like in our patient.

The purpose of the compression use during pregnancy is to reduce edema formation and to support the mecahically impaired venous flow, which is additionally hampered by the influence of hormones on the venous wall, and functional calf muscle pump insufficiency [5]. The overloading with extravasation öeads to sn overloading of the lympatics resulting in"phlebolymphedema" demonstrating a positive Stemmer sign. Wearing compression regularly especially during physical activities, improves also the lymphatic system deficiency and quality of life reducing the swelling and leg symptoms. The level of compliance to CG wearing appears positively and significantly linked to the initial level of severity of the edema [5] like in our patient who accepted a moderate compression in daily practice for a long time.

\section{Conlusion}

Compression during pregnancy and postpartum period in women with leg oedema is a justifiable recommendation.

\section{References}

1. Bamigboye A, Hofmeyer G (2006) Interventions for leg edema and varicosities in pregnancy. What evidence? Eur J Obstet Gynecol Reprod Biol 129(1): 3-8

2. Ratiu A, Motoc A, Pa^scut D, Cris xan DC, Anca T, et al.(2009) Compression and walking compared with bed rest in the treatment of proximal deep venous thrombosis during pregnancy. Rev Med Chir Soc Med Nat Lasi; 113(3): 795-8.

3. Rabe E, Partsch H, Hafner J, Lattimer C, Mosti G, et.al.( 2017) Indications for medical compression stockings in venous and lymp hatic disorders: An evidence-based consensus statement. Phlebol 2017; 33(3): 163184.

4. Sander A, Hajer N, Hemenway K, Miller A (2002) Upper-extremity volume measurements in women with lymphedema: a comparison of measurements obtained via water displacement with geometrically volume. Phys Ther 82(12): 1201-1212.

5. Allegra C, Antignani P, Will K Allaert F (2014) Acceptance, compliance and effects of compression stockings on venous functional symptoms and quality of life of Italian pregnant women. Intern Angiology 33(4): 357-364.

6. Ochalek K, Pacyga K, Curylo M, Frydrych-Szymonik A, Szygula Z, et al. (2017) Risk Factors Related to Lower Limb Edema, Compression, and Physical Activity during Pregnancy. A retrospective Study. Lymphat Res Biol 15(2): 166-171. 
Your next submission with Juniper Publishers will reach you the below assets

- Quality Editorial service

- Swift Peer Review

- Reprints availability

- E-prints Service

- Manuscript Podcast for convenient understanding

- Global attainment for your research

- Manuscript accessibility in different formats ( Pdf, E-pub, Full Tsext, Audio)

- Unceasing customer service

Track the below URL for one-step submission https://juniperpublishers.com/online-submission.php 